\title{
THE GHRELIN SYSTEM; BEYOND THE ROLE IN ENERGY HOMEOSTASIS
}

\author{
Ljiljana Šaranac ${ }^{1}$, Zoran Gucev² \\ ${ }^{1}$ Faculty of Medicine, University of Niš, Serbia \\ ${ }^{2}$ Medical Faculty Skopje, Skopje, Macedonia
}

\begin{abstract}
The fascinating story of ghrelin started more than 30 years ago with the discovery of synthetic (nonnatural) growth hormone $(\mathrm{GH})$ releasing peptides. Scientists were searching for a novel peptide, ligand of orphan GH secretagogue receptor. The discovery of ghrelin is a typical example of reverse pharmacology. The new peptide quickly attracted a lot of attention by its pleiotropic nature, and provoked a burst of new enthusiasm among scientists and clinicians. Ghrelin is mainly produced in the stomach from a distinct group of endocrine cells located within the gastric oxyntic mucosa. It acts as hunger signal and long-term body weight regulator. But, ghrelin is much more than just a natural orexigenic factor and GH secretagogue. It exerts major peripheral endocrine and non-endocrine actions, and it has a role in learning and memory, glucose homeostasis, immunity, cardio protection, fertility and addiction. Exploring the actions of ghrelin and ghrelin agonists and receptor antagonists or reverse agonists could establish new treatment options for so far incurable diseases.
\end{abstract}

Key words: Ghrelin, energy homeostasis, obesity, anorexia nervosa, ghrelin application, sepsis.

\section{Introduction}

The discovery of ghrelin allowed us to intrigue our students at the very beginning of the lecture with the fact that even stomach has endocrine properties.

The ghrelin-ghrelin receptor system is one of the most important mechanisms regulating energy balance and metabolism. The discovery of ghrelin in 1999 by Kojima group opened new era in energy homeostasis investigation and held the promise for new therapeutic options for a variety of health problems assigned as leading causes of morbidity and mortality all over the world [1,2].

Identified as a natural ligand for GHsR (Growth Hormone secretagogue Receptor), the small peptide provoked a burst of new enthusiasm among scientists and clinicians.

The Precursor of ghrelin is preproghrelin which is consisted of 117 amino acids. Ghrelin is present in two formes: acylated and non- acylated, both of them with remarkable activity. The ghrelin O-acyltransferase enzyme (GOAT enzyme) is critical in switching from one form to another. Furthermore the mystery is even more provocative by discovery of obestatin as the product of the same ghrelin gene, with the reciprocal activity [2].

Ghrelin is mainly produced in the stomach from a distinct group of endocrine cells located within the gastric oxyntic mucosa. Intestinal mucosa and pancreas are also

*Correspondence to: Prof. Ljiljana Šaranac, MD, PhD

Faculty of Medicine, University of Niš,

81 Dr. Zoran Đinđić Blvd, 18000 Niš, Serbia

Phone: +381 184226644

E-mail: endoljilja@yahoo.com

Received January $18^{\text {th }}, 2017$, accepted for publication January $29^{\text {th }}, 2017$ capable of producing a certain amount of ghrelin. The expression of ghrelin within the brain, pituitary, thyroid gland, testis, kidney and placenta suggests the pleiotropic nature of ghrelin action [1-3].

Several hormones, including peptide YY, pancreatic polypeptide, oxyntomodulin, glucagon-like peptide-1 and cholecystokinin act as satiety signals. Only ghrelin, a small opioid peptide produced by the stomach, functions as putative hunger gut signal appearing to act both as meal initiator and a long-term body weight regulator [4].

\section{Ghrelin Discovery}

Kojima et al. discovered ghrelin in 1999 as 28-amino acid peptide from the rat stomach extracts. Many researches were hunting for this hormone, but discovery took a long time.

The story of ghrelin, from the initial development of an artificial GHS (growth hormone secretagogue) to the identification of the endogenous ligand, is a typical example of the general paradigm of reverse pharmacology [1]. This story also makes the investigators reevaluate the importance of purification of natural substances. By scanning genomic databases, some amino acid sequences could be identified, but natural substances sometimes escape. Ghrelin is such a case. Kojima's team had been searching for novel unknown peptides for almost 30 years. They discovered the opioid peptides ( $\alpha$-neoendorfin), neuromedins and the natriuretic peptide family. As Kojima said, it was very exciting to find a novel peptide and explore unknown physiological functions. From the beginning of 1998, they had been searching for the endogenous ligands 
of several orphan receptors, although none of the ligands except for ghrelin have yet been discovered [5]. Professional luck or intuition led Kojima to switch the search from brain to stomach and to make great discovery. The new peptide was named ghrelin according "ghre", the Proto-Indo-European root of the word ,grow“ [5].

\section{Secretion and Receptor Distribution}

Two thirds of gastric mucosa, the epsilon cells of the gut and pancreas, pituitary, thyroid, kidney, lung, brain and even lymphocytes produce ghrelin. Secretory granules containing "X/A-like"-cells, recognized in gastric mucosa since 1960 are in fact ghrelin cells. They represent about $20 \%$ of the endocrine population in adult oxyntic glands. Ghrelin-immunoreactive cells are also found in the duodenum, jejunum, ileum and colon, gradually decreasing from duodenum to colon. Secretion of ghrelin has been also proven in rat hypothalamic and pancreatic cells [3]. The human ghrelin gene is located on chromosome 3p25-26. Mature ghrelin mRNA contains two transcripts (A and $\mathrm{B}$ ). Translation produces ghrelin precursor consisting of ghrelin (28 amino acids) and obestatin (117 amino acids), further exposed to cleavage and acyl modification. Receptors (GHsR) $1 \mathrm{a}$ and $1 \mathrm{~b}$ encoded by gene located on $3 q 26.31$ are widespread including tumors and metastases. Effects include local and systemic responses [6]. GHsR1a is G-protein coupled receptor (GPCR) expressed in the brain as well as other areas of the body. Ghrelin receptor mRNA is prominently expressed in the arcuate (ARC) and venromedial (VMN) and in hippocampus [1]. Ghrelin activation of the ghrelin receptor, GHs-R1a, has many regulatory effects on physiology and behavior, such as enhancement of memory and learning, neuroprotection, immune function improvement, blood glucose control, potentiation of food and drug addiction, and cardiovascular and renal protection [2-8]. The existence of ghrelin and its receptor in the hippocampus, a region associated with learning and memory, suggests the role of ghrelin in memory formation [1].

\section{Factors Influencing Ghrelin Secretion}

Ghrelin secretion is increased by starvation, in anorexia nervosa, low BMI conditions, and during sleep. Leptin, GHRH, thyroid hormones, testosterone stimulate ghrelin secretion, while somatostatin, insulin, PYY and PP are inhibiting it. Ghrelin concentration is low in obese subjects, after food intake, in conditions accompanied by high glucose and lipid levels [1-5]. Stomach strech is not a stimulus for ghrelin inhibition which was proven by filling rat stomach with water after starvation. However the addition of dextrose did decrease ghrelin secretion, suggesting that hypoglycemia itself might be the stimulus for ghrelin release [6-9].

Helicobacter pylori infection of gastric mucosa could have a negative impact on ghrelin production and secretion, but opposite results are also published [10,11]. Weight gain following Helicobacter pylori eradication may be attributable to changes in plasma and gastric ghrelin; however, this hypothesis needs to be further investigated [12].

\section{Ghrelin Action}

Discovered as a potent GH secretagogue, ghrelin quickly demonstrated its pleiotropic nature. Opposite to leptin it stimulates food intake and rises BMI in rodents and humans (Fig 1). In fact this hormone is one of the most important factors regulating appetite and energy expenditure. Ghrelin is also known as starvation hormone; potent orexigenic signal acting via NPY/ Agouti Related Peptide (AGRP) and orexine neurons stimulation in nucleus arcuatus. Investigation of fasting and feeding on human plasma levels of ghrelin showed peak values after 12 hours of starvation, achieving sharp fall after 30 minutes of meal intake. Three hours later ghrelin is gradually reversed to the starting peak value. Furthermore ghrelin is a trigger for other neuroendocrine, metabolic and nonendocrine actions [13].

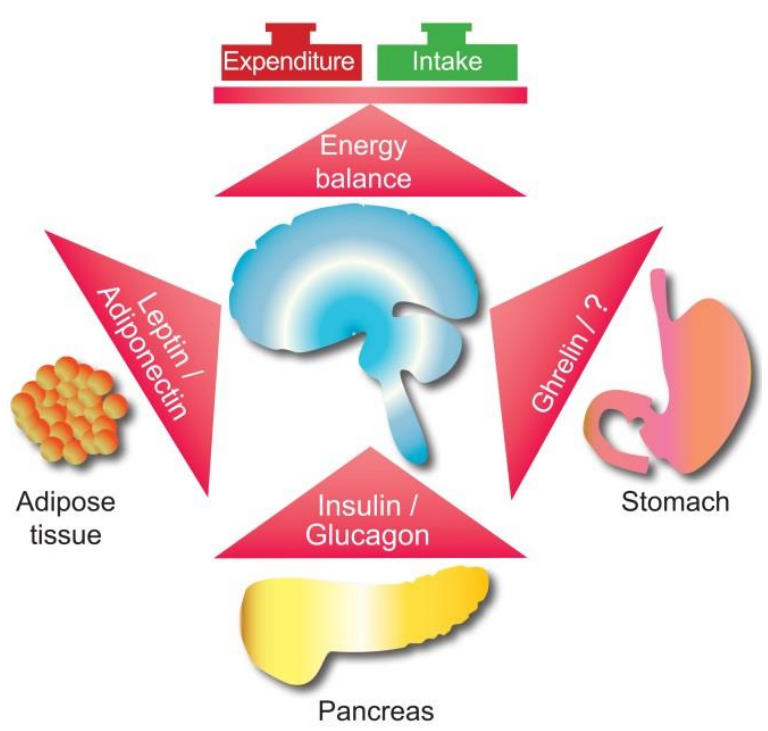

Fig. 1 Control of energy balance.

Both peripheral and central administration of ghrelin potently promotes body weight gain and adiposity through a stimulation of food intake while decreasing energy expenditure and body fat utilization [14].

\section{Endocrine Effects}

Among central effects the most prominent are appetite stimulation and stimulation of growth hormone release. Actually, ghrelin provides at the same time GH release and calories that $\mathrm{GH}$ needs for growth and repair. $\mathrm{GH}$ releasing activity results from dual action, one synergistic with GHRH and another through the inhibition of somatostatin. Ghrelin modulates lactotropic and corticotropic activity, provoking ACTH, cortisol and PRL stimulation. Additionally, it controls insulin secretion and influences thyroid function and reproduction $[15,16]$. 
Metabolic actions of $\mathrm{GH}$ and ghrelin are complementary. GH stimulates protein synthesis, preserves carbohydrates and stimulates energy expenditure acting by favorizing lipolysis and fatty acids oxidation in calories replete, fed state. In starvation ghrelin levels are high, acting as stimulator of energy intake and inhibitor of energy expenditure, and, at the same time, spending calories from carbohydrate intake. Additionally it stimulates glucose output by hepatocytes.

Although a potent $\mathrm{GH}$ releasing agent ghrelin is not necessary for longitudinal growth. Namely ghrelin knockout mouse unexpectedly grows with normal velocity, reflecting thus the complexity of the regulation of $\mathrm{GH}$ system. The phenotype of ghrelin knock-out mouse includes normal size, growth rate, food intake, body composition, reproduction, and gross behavior, without any pathological changes. It could be explained by the fact that survival is more threatened by starvation than obesity [2].

However, the ghrelin-null mouse showed a significant reduction in body fat mass when the animal was fed with the high fat diet. Thus it is interesting to explore ghrelin level in idiopathic short stature [5,16,17].

\section{Ghrelin, Endocrine Pancreas, Glucose and Lipid Metabolism}

Endocrine pancreas is the main source of the ghrelin during fetal life. Acylated and non acylated forms show opposite effect on glucose metabolism. Obestatin exhibits counter effect from acylated form. Ghrelin modulates both, exocrine and endocrine pancreatic functions. Insulin level is reduced, but glucagon level remains unchanged $[3,5]$. It is expressed in pancreatic cells and inhibits insulin release in mice, rats and humans. Ablation of ghrelin, GHsR or GOAT enhances insulin release. This insulin static action of ghrelin/GHsR system could optimize the amount of insulin release on systemic demand. The ghrelin blockade counteracts the obesity associated glucose intolerance in both, the life stylerelated and genetic obese models.

In healthy humans, total ghrelin levels are negatively associated with skeletal muscle mass, the fact that suggest a detrimental role on insulin sensitivity explored in human, animal and cellular models [15].

Effects on adipose tissue could shortly be summarized as following: adypogenic effect, lipolysis inhibition, influence on adipocyte proliferation, differentiation and apoptosis, regulating total number of adipocytes. The signalization is through MAPK and PI3K/Akt.

\section{Ghrelin as Link between Energy Balance and Fertility}

Ghrelin is more than orexigenic signal and GH secretagogue. It influences gonadal axis and the onset of puberty. It is well known that puberty onset and reproduction are metabolically gated. Conditions of starvation are associated with perturbations in the timing of puberty and subfertility. Thus ghrelin which operates as a signal of energy insufficiency and functional antagonist of leptin, may play a physiological and eventual pathophysiological role in the regulation of puberty onset and gonadal function [17]. Ghrelin receptors are identified in Leydig cells and follicular ovarian cells. It exerts inhibitory role on testosterone and LH secretion. PRL secretion is stimulated by ghrelin direct action on pituitary somatomammotroph cells. It is slight and dose-dependent PRL secretion. Ghrelin has been reported to exert an inhibitory effect on follicle-stimulating hormone, an, in particular, on luteinizing hormone, probably via an inhibitory effect exerted at the hypothalamic level on gonadotropinreleasing hormone secretion [18].

\section{Ghrelin and Long Term Regulation of Energy Homeostasis}

Ghrelin is braking boundaries between short-term and long-term regulating signals in energy balancing. Modulatory effect of both forms of ghrelin, acylated and non acylated on adipogenesis is well documented. It has been shown that both forms of ghrelin directly promote adipogenesis in rat bone marrow adipocytes [19,20). Although the orexigenic action of ghrelin itself predicts impact on weight gain, ghrelin has also been shown to be able to directly act at the level of endocrine pancreas, liver and adipose tissue, thus modulating glucose and lipid metabolism $[4,5,9]$. Plasma levels of ghrelin are generally negatively correlated with body weight and increase in response to fasting with a subsequent decrease upon refeeding. In humans, ghrelin concentrations progressively decrease during childhood and adolescence, as well as with advancing puberty. In adolescents, similar to adults, ghrelin concentrations are inversely related to BMI and to circulating insulin [21-24]. One notable exception is the presence of elevated ghrelin concentrations in subjects with Prader-Willi syndrome, raising the possibility that ghrelin could be part of the etiology of excess food intake in this condition [25].

Due to ghrelin's ability to promote body weight gain and adiposity via centrally mediated signaling mechanisms, modulation of the endogenous ghrelin system is considered a promising strategy to treat individuals with pathologically reduced body weight. 


\section{Ghrelin and Sepsis}

Even in modern Intensive Care Units (ICU), sepsis is the leading cause of mortality. Sepsis is characterized by hemodynamic perturbation as well as excessive production of proinflammatory cytokines resulting in multiple organ dysfunction. Acute kidney injury (AKI) in septic patients increases the mortality to $50-80 \%$. Therefore it is of survival importance to identify potential therapeutic interventions with the capability to attenuate sepsis related acute renal insufficiency. Ghrelin inhibits proinflammatory cytokine release (IL-1, IL-6 and TNFalfa) as well as endotheline activity responsible for vascular perfusion. Ghrelin improves tissue perfusion in severe sepsis via downregulation of endothelin-1. Gramnegative bacteria endotoxin is known to cause most of hemodynamic and inflammatory responses [26-29]. In addition to any hemodynamic benefit of ghrelin in protecting against endotoxin-induced AKI, the agent's anti-inflammatory properties are no doubt critical. There are experimental data that ghrelin protects against experimental sepsis by inhibiting High-Mobility Group Box 1 (HMGB1) release and by killing bacteria. HMBG is secreted by activated monocytes and macrophages in humans and animals with sepsis and endotoxemia, acting as late proinflammatory factor. In animal models of sepsis, ghrelin improved bacterial clearance in vivo and showed bactericidal properties in vitro [28). Thus, ghrelin emerges as a natural antimicrobial and anti-inflammatory peptide, widely distributed in all body tissues and especially abundant in the proximity to physical barriers such as stomach, gut, and skin suggesting that one of its primary functions could be related to the control of innate immunity and response against infections [29-31].

\section{Ghrelin, an Addiction Hormone}

The essential goal of feeding is to provide calories and a diversity of nutrients. However, we do not eat only for energy, we also eat for pleasure. Almost all circulating gut peptides contribute to the control of food intake by signaling satiety. One important exception is ghrelin, the only orexigenic peptide hormone so far described. Ghrelin interacts with the brain reward pathways to increase food intake, alter food preference and enhance food reward, thus influencing hedonic feeding control $[32,33]$.

Evidence is accumulating linking obesity as an environmental risk factor to psychiatric disorders such as stress, anxiety and depression. Plasma ghrelin levels are enhanced under conditions of physiological stress and ghrelin has recently been suggested to play an important role in stress-induced food reward behavior. In addition, chronic stress or atypical depression has often demonstrated to correlate with an increase in ingestion of caloric dense foods [34,35]. Recent evidence suggests ghrelin as a critical factor at the interface of homeostatic control of appetite and reward circuitries, modulating the hedonic aspects of food intake. Therefore, the reward-related feeding of ghrelin may reveal itself as an important factor in the development of addiction to certain foods, similar to its involvement in the dependence to drugs of abuse, including alcohol. Thus the ghrelinergic system could be an effective target for the development of successful anti-obesity pharmacotherapies, which not only affects appetite but also selectively modulates the rewarding properties of food and impact on psychological well-being in conditions of stress, anxiety and depression [33-37].

\section{Ghrelin and the Cardiovascular System}

The cardiovascular system has also been recognized as important target for ghrelin effects. A single injection of ghrelin provokes a significant decrease in blood pressure, without changing the heart rate, acting as antagonist of endothelin-1 [2,38]. In experimental models ghrelin showed cardioprotective effect against ischemia. Apart from vasodilatory effects, ghrelin may also have other vasoactive and anti-inflammatory properties and could be considered as therapeutic agent in conditions with atherosclerosis [39]. In hypophysectomized rats pretreated with $\mathrm{GH}$ secretagogues heart damage was prevented. Possible anti-apoptotic effects have also been studied on cardiomyocytes and endothelial cells in vitro. In rats with experimental myocardial infarction, ghrelin treatment improved cardiac output [40-42]. Chronic heart failure (CHF) remains one of the most challenging therapeutic problems, regarding frequency in ICU and high mortality rate, particularly so, if the CHF patient develops cardiac cachexia. Ghrelin and its analogs have been suggested to improve body weight and cardiac function in heart failure models [43].

\section{In whom to Determine Ghrelin?}

Taking into account all above it is of practical importance to suggest in whom to investigate circulating ghrelin levels. In our opinion it is crucial to determine ghrelin or ghrelin/leptin ratio in lean subjects with abundant intake of energy dense food, searching for clue in achieving healthy balance in orexitropic signaling [44]. Obese and cachectic subjects are also candidates in order to rule out possible resistance syndromes as well as in addiction syndromes.

With regard to children, SGA, IUGR neonates, septic children, patients with idiopathic short stature are certainly good candidates for ghrelin determination, being the population that deserves better understanding of their pathological conditions and opening new therapeutic approaches.

Recently, we have found an important difference in appetite targeting hormones, ghrelin and leptin, and their profiles in a study group that included 88 children and adolescents aged 6 to17.67 years, classified as obese (30 subjects), undernourished (25 subjects) and lean (33 subjects). Two orexitropic hormones showed different profiles in 3 different nutritional conditions; an inverse relationship was discovered between study groups in ghrelin/leptin and leptin/ghrelin ratios (unpublished data). 


\section{Clinical Application of Ghrelin}

Due to its adipogenic, orexigenic and diabetogenic activities, ghrelin has emerged as an attractive target for the treatment of different pathological conditions (Tab. 1). Unacylated ghrelin agonists in animal and human studies exerted improvement in post-prandial glucose and insulin sensitivity, as well in prevention of fat accumulation. GOAT inhibitors have potential to decrease plasma acylated ghrelin, consequently resulting in reduction of blood glucose and weight gain. AG antagonists and blockers in animal and human models decrease AG central activity assessed by inhibition of GH secretion [45].

Table 1 Clinical application of ghrelin

\begin{tabular}{lll}
\hline UG & control of PPG & $(45)$ \\
GOAT inhibitors & BM and BG reduction & $(45)$ \\
Ghrelin agonists & GHD diagnosis & $(2,5)$ \\
Ghrelin agonists & AN treatment & $(47,48,50)$ \\
& AIDS, Cardiac cachexia & $(1,43,46)$ \\
& Cancer cachexia & $(43,45,46)$ \\
Ghrelin antagonists & Obesity & $(45,46,49)$ \\
& Prader -Willi Sy & $(25)$ \\
Ghrelin analogs & Gastroparesis & $(51)$ \\
& Postoperative ileus & $(51)$ \\
Ghrelin & Sepsis (animals) & $(29,30,31)$ \\
\hline
\end{tabular}

UG - Unacylated ghrelin, GOAT - ghrelin O - acyltransferase enzyme, PPG - postprandial glucose, AN - Anorexia nervosa

Ghrelin offers great potential for clinical application in diagnosis of pituitary function in GH deficiency, in eating disorders like anorexia and bulimia nervosa as well as in Prader-Willi syndrome, gastrointestinal diseases,

\section{References}

1. Kojima M, Hosoda $\mathrm{H}$, Date $\mathrm{Y}$, Nakazato $\mathrm{M}$, Matsuo $\mathrm{H}$, Kangawa K. Ghrelin is a growth-hormone-releasing acylated peptide from stomach. Nature 1999; 402:656-660.

2. Kojima M, Kingawa K. Ghrelin structure and function. Physiol Rev 2005; 85:405-522.

3. Sato T, Nakamura Y, Shimura Y, Ohgusu H, Kangawa K, Kojima M. Structure, regulation and function of ghrelin. J Biochem 2012; 151(2):119-128.

4. Wren A. Gut and hormones and obesity. Fron Horm Res 2008; 36:165-181.

5. Kojima M, Kangawa K. Ghrelin discovery: a decade after. In: The ghrelin system. Benso A, Casaneuva FF, Ghigo E, Granata A Eds Endocr Dev Basel, Karger 2013; 55:1-4.

6. Reimer MK, Pacini G, Ahren B. Dose dependent inhibition by ghrelin of insulin secretion in the mouse. Endocrinology 2003; 144:916-921.

7. Tong J, Prigeon RI, Davis HW, Bidlingmaier M, Kahn SE, Cumming DE, Tschop MH, D’Alessio D. Ghrelin suppresses glucose-stimulated insulin secretion and deteriorates glucose tolerance in healthy humans. Diabetes 2010; 59: 2145-2151

8. Albararan-Zeckler R, Smith R. The ghrelin receptors (GHSR1a and GHS-R1b). In: Benso A, Casaneuva FF, Ghigo E, Granata A (eds) The ghrelin system. Endocr Dev Basel: Karger 2013; 55:5-15.

9. Inui A. Ghrelin: an orexigenic and somatotrophic signal from the stomach. Nat Rev Neurosci 2001; 2:551-560. cardiovascular disease (heart failure and dilated cardiomyopathy), osteoporosis, in aging, in catabolic state or chronic wasting syndrome, in cachexia (cancer and cardiac cachexia), AIDS, postoperative patients $[1,43,46]$. Anamorelin, an oral ghrelin receptor agonist with appetite enhancing and anabolic activity is recently successfully applied in anorexia-cachexia syndrome $[47,48]$.

At present, ghrelin is a unique peripheral orexigenic signal that is effective upon its intravenous injection. Thus blocking or neutralizing ghrelin's action may be a reasonable approach to reversing a chronic obesity $[46,49]$.

In Japan, ghrelin receptor agonist is clinically used as diagnostic agent for growth hormone secretion deficiency. Recently, it has also been used as therapeutic agent in patients with severe form of anorexia nervosa. One-year intra-nasal application of such agonist in a severely emaciated AN patient improved hypoglycemia and body weight [50].

Repeated administration of ghrelin can stimulate appetite in patients with functional dyspepsia. Ghrelin also accelerates gastric emptying in diabetic gastroparesis and postoperative ileus after partial colectomy. Therefore, ghrelin analogs could represent a new class of prokinetic agents in the future [51]. However, most ghrelin compounds are peptides and need to be injected several times per day, which affects the quality of life of patients in human clinical studies.

Ghrelin, ghrelin agonists, receptor antagonists and reverse agonists are certainly potential diagnostic and therapeutic options for the future.

Acknowledgment: Supported by a grant from the Ministry of Education, Science and Technological Development of the Republic of Serbia No 31060.

10. Jeffery PL, McGuckin MA, Linden SK. Endocrine impact of Helicobacter pylori: focus on ghrelin and ghrelin o-acyltransferaze. World J Gastroenterol 2011; 17(10):1249-1260.

11. Ghigo E, Arvat E, Broglio F, Giordano R, Gianotti L, Muccioli G, Papotti M, Graziani A, Bisi G, Deghenghi R, Camanni F: Endocrine and non-endocrine activities of growth hormone secretagogues in humans. Horm Res 1999: 51(Suppl 3):9-15.

12. Gokcel A, Yuksel Gumurdulu1 Y, Fazilet Kayaselcuk F, Ender Serin E, Birol Ozer B, Kursad Ozsahin A, Guvener N. Helicobacter pylori has no effect on plasma ghrelin levels. Eur J Endocrinol 2003; 148:423-426.

13. Tschop M, Smiley D, Heiman M. Ghrelin induces adiposity in rodents. Nature 2000; 407:908-913.

14. Boltin D, Niv Y. Ghrelin, Helicobacter pylori and body mass: is there association? Reviews 2012; 14: 130-132.

15. Andrich D, Cianflone K, Comtois AS, St-Pierre D. The endocrine effects of acylated and des-acylated ghrelin. Research and Reports in Endocrine disorders 2012; 2:31-40.

16. Iniguez G, Roman R, Youlton R, Cassorla F, Mericq V. Ghrelin plasma levels in patients with idiopathic short stature. Horm Res Pediatr 2011; 75:94-100.

17. Tena-Sempere M. Ghrelin, the gonadal axis and the onset of puberty. In: Benso A, Casaneuva FF, Ghigo E, Granata A (eds) The ghrelin system. Endocr Dev. Basel, Karger 2013; 25:69-82. 
18. Benso A, Calvi E, Gramaglia E, Olivetti I, Tomelini M, Ghigo E, Broglio F. Other than growth hormone neuroendocrine actions of ghrelin. In: Benso A, Casaneuva FF, Ghigo E, Granata A (eds) The ghrelin system. Endocr Dev. Basel, Karger 2013; 25:59-68.

19. Thompson NM, Gill DA, Davies R, Loveridge N, Houston PA, Robinson IC, Wells T. Ghrelin and des-octanoyl ghrelinpromote adipogenesis directy in vivo by mechanism independent of the type 1a growth hormone secretagogue receptor. Endocrinology 2004; 145:234-242.

20. Muccioli G, Pons N, Ghe C, Catapano F, Granata R, Ghigo E. Ghrelin and des-acyl ghrelin both inhibit isoproterenol-induced lipolysis in rat adipocytes via a non-type 1a secretagogue receptor. Eur J Pharmacol 2004; 498:27-35.

21. Chanoin JP. Ghrelin in growth and development. Horm Res 2005; 63:129-138.

22. Wali P, King J, He Z, Tonb D, Horvath K. Ghrelin and obestatin level in children with failure to thrive and obesity. $\mathbf{J}$ Pediatr Gastroenterol Nutr 2014; 58:376-381.

23. Shen $\mathrm{C}, \mathrm{Yu} \mathrm{T}$, Tang $\mathrm{ZH}$, Wu KM. Changes in ghrelin and obestatin levels before and after a meal in children with simple obesity and anorexia. Horm Res Pediatr 2013; 79(6):341-6.

24. Arrigo T, Gitto E, Ferraù V, Munafò C, Alibrandi A, Marseglia GL, Salpietro A,Miraglia Del Giudice M, Leonardi S, Ciprandi G, Salpietro C. Effect of weight reduction on leptin, total ghrelin and obestatin concentrations in prepubertal children. $\mathbf{J}$ Biol Regul Homeost Agents. 2012; 26(1 Suppl):S95-103.

25. Feigerlová E1, Diene G, Conte-Auriol F, Molinas C, Gennero I, Salles JP, Arnaud C, Tauber M. Hyperghrelinemia precedes obesity in Prader-Willi syndrome. J Clin Endocrinol Metab. 2008;93: 2800-2805.

26. Wang W, Bansal Shweta B, Falk S, Ljubanovic D, Schrier R. Ghrelin protects mice against endotoxemia- induced acute kidney injury. Am J Physiol Renal Physiol 2009; 297: F1032-F1037.

27. Wu R, Dong M, Zhou X, Cui H, Simons H, Wang P. Ghrelin improvestissue perfusion in severe sepsis via downregulation of endothelin-1. Cardiovascular Res 2005; 68:318-326.

28. Chorny A, Anderson P, Gonzales-Rey E, Delgado M. Ghrelin protects against experimental sepsis by inhibiting Highmobility group box 1 release and by killing bacteria. $\mathrm{J}$ Immunol 2008; 180:8369-8377.

29. Yang WL, Ma G, Zhou M, Aziz M, Yen HT, Mavropoulos S, Ojamaa K, Wang P. Combined administration of human ghrelin and human growth hormone attenuates organ injury and improves survival in aged septic rats. Mol Med 2016; 22: 124-135. doi: 10.2119/molmed.2015.00255.

30. Inoue S, Suzuki K, Komori Y, Morishita Y, Suzuki-Utsunomiya K, Hozumi K, Inokuchi S, Sato T. Persistent inflammation and T cell exhaustion in severe sepsis in the elderly. Crit Care 2014; 18(3):R130. doi: 10.1186/cc13941

31. Jacob A, Rajan D, Pathickal B, Balouch I, Hartman A, Wu R, Zhou M, Wang P. The inhibitory effect of ghrelin on sepsisinduced inflammation is mediated by the MAPK phosphatase1. Int J Mol Med $2010 ; 25: 159-164$.

32. Cheyuo C, Jacob A, Wang P. Ghrelin-mediated sympathoinhibition and suppression of inflammationin sepsis. Am J Physiol Endocrinol Metab 2012; 302:E265-E272.

33. Menzies J, Skibicka K, Leng Gareth. Ghrelin, reward and motivation. In: Benso A, Casaneuva FF, Ghigo E, Granata A (eds) The ghrelin system. Endocr Dev. Basel, Karger 2013; 25: 101-111.

34. Schellekens H, Finger BC, Dinan TG, Cryan JF. Ghrelin signalling and obesity: at the interface of stress, mood and food reward. Pharmacol Ther 2012; 135:316-326.
35. Schellekens H, Dinan TG, Cryan JF. Taking two to tango: a role for ghrelin receptor heterodimerization in stress and reward. Front Neurosci 2013; 7:1-18.

36. Depoortere I. Targeting the ghrelin receptor to regulate food intake. Regul Pept 2009; 91: 285-323.

37. Engel JA, Nylander I, Jerlhag E. A ghrelin receptor (GHS-R1A) antagonist attenuates the rewarding properties of morphine and increases opioid peptide levels in reward areas in mice. Eur Neuropsychopharmacol 2015; 25:2364-2371.

38. Nagaya N, Kojima M, Uematsu M, Yamagushi M, Hosoda H, Oya H, Hayashi Y, Kangawa K. Hemodynamic and hormonal effects of human ghrelin in healthy volunteers. Am J Physiol Regul Integr Comp Physiol 2001; 280:R1483-R1487.

39. Li WG, Gavrila D, Liu X, Wang L, Gunnlaugsson S, Stoll LL, McCormick ML, Sigmund CD, Tang C, Weintraub NL. Ghrelin inhibits proinflammatory responses and nuclear factor-kappaB activation in human endothelial cells. Circulation 2004; 109 2221-2226.

40. Locatelli V, Rossoni G, Schweeiger F, Torsello A, De Gennaro Colonna V, Bernarreggi M, Deghenghi R, Muller EE, Berti F. Growth hormone independent cardioprotective effects of hexarelin in the rat. Endocrinology 1999; 140:4024-4031.

41. Nagaya N1, Uematsu M, Kojima M, Ikeda Y, Yoshihara F, Shimizu W, Hosoda H, Hirota Y, Ishida H, Mori H, Kangawa $\mathrm{K}$. Chronic administration of ghrelin improves left ventricular dysfunction and atenuates development of cardiac cachexia in rats with heart failure. Circulation 2001: 104(12):1430-1435.

42. Isgaard J. Ghrelin and the cardiovascular system. In: Benso A, Casaneuva FF, Ghigo E, Granata A (eds) The ghrelin system. Endocr Dev. Basel, Karger 2013; 25:83-90.

43. Palus S, von Haehling S, Doehner W, Datta R, Zhang J, Dong JZ, Culler MD, Anker SD, Springer J. Effect of application route of the ghrelin analog BIM-28131 (RM-131) on body weight and body composition in a rat heart failure model. Int $J$ Cardiol 2013; 168:2369-2374.

44. Saranac L, Bjelakovic B, Stamenkovic H, Kamenov B. Orexitropic signaling proteins in obese children. The Scientific World Journal 2007; 7:1263-1271.

45. Allas S, Abribat T. Clinical Perspectives for ghrelin-derived therapeutic products. In: Benso A, Casaneuva FF, Ghigo E, Granata A (eds) The ghrelin system. Endocr Dev. Basel, Karger 2013; 25:157-166

46. Drazen DL, Woods SC. Peripheral signals in the control of satiety and hunger. Curr Opin Clin Nutr Metab Care 2003; 6: 621-629.

47. Garcia JM, Boccia RV, Graham CD, Yan Y, Duus EM, Allen S, Friend J. Anamorelin for patients with cancer cachexia: an integrated analysis of two phase 2, randomised, placebo-controlled, double-blind trials. Lancet Oncol 2015; 16:108-116.

48. Bai Y, Hu Y, Zhao Y, Yu X, Xu J, Hua Z, Zhao Z. Anamorelin for cancer anorexia-cachexia syndrome: a systematic review and meta-analysis. Support Care Cancer 2017, Jan 10. doi: 10.1007/s00520-016-3560-0. [Epub ahead of print]

49. Ukkola O. Peripheral regulation of food intake: new insights. J Endocrinol Investig 2004; 27:96-98.

50. Haruta I, Fuku Y, Kinoshita K, Yoneda K, Morinaga A, Amitani M, Amitani H, Asakawa A, Sugawara H, Takeda Y, Bowers CY, Inui A. One-year intranasal application of growth hormone releasing peptide- 2 improves body weight and hypoglycemia in a severely emaciated anorexia nervosa patient. J Cachexia Sarcopenia Muscle 2015; 6:237-241.

51. Tseng PH, Wu MS, Kao JH. Recent advances in clinical application of gut hormones. J Formos Med Assoc 2010; 109: 859-861. 